\title{
Postpollination Reproductive Biology of Rhododendron prinophyllum (Small) Millais
}

\author{
Julie Padrutt' ${ }^{1}$, Harold Pellett, and Peter Ascher \\ Department of Horticultural Science, University of Minnesota, St. Paul, MN 55108 \\ Additional index words. self-incompatibility, inbreeding depression, evolution
}

\begin{abstract}
Complete diallel matings were performed during two consecutive seasons in a full sibling population of Rhododendron prinophyllum, the pinkshell azalea. Examination of pollen tubes from collected and fixed styles revealed no differences in growth, rate of pollen tubes between selfs and outcrosses. Penetration of pollen tubes through the ovular micropyle region occurred 4 to 7 days after pollination, regardless of pollen source. Embryogenesis was studied in pistils collected from forced greenhouse plants of the same population. All ovules appeared to develop for a short period before senescing. Percent capsule set data from both years' diallel pollinations indicated that some active form of self-recognition and rejection was operating and that environmental stresses and resource allocation were also influential. Additional information gathered included ovule counts, seed count to capsule size correlations, and germination trials. These pointed to a reduction in reproductive success at each developmental stage. Self-incompatibility (SI), defined as inability to set seed following self-pollination, is clearly not applicable here. There are inherent difficulties in separating an active, late-acting self-recognition/rejection system from inbreeding depression, which is a passive accumulation of homozygous recessive lethal and sublethal genes.
\end{abstract}

A major emphasis in Rhododendron research has been to describe and explain intersectional hybrid failure (Creech, 1955; Kho and Baer, 1970; Williams et al., 1982). The selfing behavior of Rhododendron is also poorly understood. An extensive examination of selfing in three species of Rhododendron, including studies of self and cross pollen tubes, showed no difference in rate of pollen tube growth between the two. Williams et al. (1985) suggested that a more generalized postzygotic abortion, perhaps reminiscent of inbreeding depression, was operating instead of classic self-incompatibility (SI).

$\mathrm{SI}$ is the failure of a fertile hermaphrodite or monoecious plant to set viable seed after self pollination. It is a genetically based, physiologically active, prefertilization barrier that prevents inbreeding and leads to outcrossing (Ascher, 1976).

Two types of SI have been described, based on the source of gene control and the associated site of the incompatibility reaction. In the sporophytic system (SSI), the haploid genotype of the pollen grain is overlain with the diploid $S$ (the incomparability locus) phenotype of the male parent. In the gametophytic system (GSI), the phenotype of the pollen grain is derived from its own haploid genotype. In either case, when a matching allele from the male gametophyte is recognized on or within the stigma of the female, no self seed will set and heterozygosity of the resulting population will be maintained.

In this study, the selfing behavior of $R$. prinophyllum, a North American species highly valued for contributions to breeding for cold hardiness in northern varieties, was examined to determine what, if any, system of incompatibility is in operation.

\section{Materials and Methods}

Rhododendron prinophyllum accession no. 790912 is a full sibling population located at the Univ. of Minnesota Landscape Arboretum in the rhododendron and azalea trial plots. The two dozen plants comprising the population are $\mathrm{F}_{1}$ seedlings arising from a cross between accessions 790577 and 790580 . While the

Received for publication 24 June 1991. Accepted for publication 11 Mar. 1992. Journal Series Paper no. 19084 of the Minnesota Agricultural Experiment Station. The cost of publishing this paper was defrayed in part by the payment of page charges. Under postal regulations, this paper therefore must be hereby marked advertisement solely to indicate this fact.

'Present address: LongWood Gardens, P.O. Box 501, Kennett Square, PA 19348. specific origin of the parents is not recorded, it is known that neither parent would set self seed. They are not considered to be related.

\section{Year 1-1986}

Field pollinations. Nine plants from a population of $R$. prinophyllum were selected in May 1986. When the population had reached $\approx 50 \%$ anthesis, nine flower clusters from each plant were emasculated; we also removed already opened flowers as well as buds still physiologically immature. The clusters were not bagged, as prior work had shown that flowers with their corollas removed, accomplished during emasculation, are not visited by insects and remain unpollinated. Two days later, each of the plants was selfed and crossed with fresh pollen from every other individual. Only one pollen type was used on each flower cluster. Number of flowers pollinated per cluster ranged from as few as six to as many as 23 . In all, 1013 pollinations were made.

Pollen tube analysis. Two days after pollination, one to three pistils were collected from each cross and fixed in FAA. The fixed material was then stored in $70 \%$ ethanol. The pistils were prepared and observed for pollen tube growth rates and stage of ovule development in both cross- and self-pollinated material with a Zeiss epifluorescence microscope (Lab. 16 model with epifluorescence condenser IUFl, Carl Zeiss, Oberkochen, Germany) and the filter combination: KP450, KP490, Ft 510, LP 520, as described by Kho and Baer (1968). Photographs were obtained with the aid of a Nikon At35 35-mm camera and Kodak Tungsten 160 film.

Capsule collection. Beginning in early October, capsules were collected as they matured, and the number of capsules was recorded for each cross. Three crosses were lost during the season and data on capsules were unavailable. Compatibility was analyzed from the 1986 crosses with the aid of SIGMAS (SelfIncompatibility Genetic Modeling Application Systems), a computer software developed by Liedl and Anderson (1987).

\section{Year 2-1987}

Field/indoor pollinations. Six plants chosen on the basis of 1986 results from the original nine plants were again labelled

Abbreviations: SI, self-incompatibility. 
and emasculated. The six plants were selected to include three plants that had set a range of self capsules and three plants that set no self capsules the previous summer. Two clusters were emasculated and pollinated for each cross for a total of 752 crosses.

To microscopically observe pollen tube growth rates following selfing and crossing, branches from a plant with no self capsules, no. 9, (Fig. 3) and from the highest self-capsule setting plant, no. 8, (Fig. 3) were cut and brought indoors for forcing where temperatures would be more uniform. As the flowers began to open, they were emasculated, and the plants were then selfed and crossed to one another. All pistils from these pollinations were collected at intervals of $6,12,18,24$, and $30 \mathrm{~h}$ after pollination and fixed in FAA for later microscopic analysis.

Capsule collection and seed counting. Capsules were again collected in fall as they matured. Total capsules per cross was recorded. The length and width of each capsule were measured using a Manostat caliper. The resulting measures were recorded and used to estimate the volume of each capsule using the formulator a cylinder.

The number of seeds per capsule was counted to estimate reproductive success. All five locules were split away from the capsule using a no. 11 surgical blade (Bard-Parker, Becton Dickinson Co., Rutherford, N.J.), and seeds were removed through the placental groove with a needle probe. Contents of each locule were counted with the aid of an OptiVisor binocular/ magnifier (Donegon Optical, Kansas City, Me.), lens no. 7 (magnification $\times 23 / 4$ ). Several samples of open-pollinated capsules from plants in the study population and capsules collected from mature plants of other $R$. prinophyllum populations were also counted and similarly measured.

Seed germination. Two 50-seed samples from each cross were tested for germination capacity. If $<100$ seeds were available, they were divided equally for the two treatments. Milled sphagnum moss was moistened with distilled water and $\approx 25 \mathrm{ml}$ placed into $100 \times 15$-mm petri dishes and teased to create a flat, uniform surface filling the plate. Seeds were soaked overnight in $1000 \mathrm{ppm}$ (treatment 1) or $500 \mathrm{ppm}$ (treatment 2) gibberellic acid (GA), drained, rinsed thoroughly, and placed on the medium. Samples were placed in germination chambers under lights at $24 \mathrm{C}$. Germinating seeds were observed with the OptiVisor, and counts were taken at 2-day intervals after germination began. The appearance of a protruding radicle was used as the start of germination. A final count was averaged between the two GA treatments to yield total percent germination.

Pollen tube analysis. Microscope examination of pollen tube growth following the 1987 crosses was made using the technique described by Williams et al. (1982) with the following modification: Under a Wild stereomicroscope, the fixed pistils were placed on a slide in ethanol, and the style and stigma were removed and returned to the collection vial. Retaining the pedicel as a handle, the ovary walls were carefully cut away from the ovules by first slicin between each locule with a no. 11 surgical blade, cutting across the base. The blade was then used to remove pieces of the ovular wall. The ovules were stored in $70 \%$ ethanol. Pollen tubes were examined following the same procedures as in 1986.

Estimating number of ovules. During dissecting away the ovary walls, a single intact locule was removed and transferred to a clean slide with potassium iodine stain, which darkened the starch and allowed easier examination of the ovules. The remaining four locules were returned to the respective collection vials along with the style. Stain was added to the dissecting slide, and any ovules lost in the dissecting process were counted. The remaining locule was halved along the placental groove, and ovules of each half were counted. The total was recorded and multiplied by five, to estimate the total number of ovules that could potentially develop into seed from each stigma pollinated.

Fertilized ovules. The remaining four locules, when cleared as described for pollen tubes, were gently teased away from the receptacle and pedicel, placed onto a clean slide with fresh aniline blue stain, and squashed under a coverslip. Ovule condition, whether fertilized or unfertilized, and development or degeneration were noted.

For additional study of ovule development following pollination, two plants from the same population were dug in Nov. 1987 before the ground had frozen. They were potted and stored in a below-ground storage facility to fulfill cold requirements, then forced into flower in a greenhouse. Upon reaching 50\% anthesis, the two plants (designated $\mathrm{A}$ and $\mathrm{C}$ ) were reciprocally crossed and selfed. Several branches were also emasculated but not pollinated on each plant to provide a control for assessing changes during development of the ovules. Pistils were barvested at $1,2,4,7,14,21$, and 28 days after pollination. The collections were treated similarly to the field material. Pollen tube growth and ovule development were observed and recorded.

\section{Results and Discussion}

Pollen tube and ovule observations. Germination of pollen tubes and penetration of the stigma surface had occurred between 1 and 2 days after pollination regardless of pollen source. No difference in growth rate between self and outcross pollen tubes was perceived.

The fixed pistils from the remaining 1987 field pollinations were first checked to be certain that pollen tetrads had germinated and the resulting pollen tubes had grown through the style. Microscopic evidence suggested that pollen tubes from self- and cross-pollinations reached the base of the style by the 3rd day. (Fig. 1 A, B, and C). Some ovules had been penetrated by pollen tubes by this time. These were readily distinguished from ovules lacking pollen tubes in that they had a linear fluorescent pollen tube segment running from the outer ovule surface, through the micropyle, and up to the embryo sac. In many instances, it was even possible to see the pollen tubes extending beyond the entrance to the ovule micropyle, making judgment of ovular condition even simpler (Fig. ID).

Collections 1 and 2 days after pollination of greenhouse plants $\mathrm{A}$ and $\mathrm{C}$ gave little new information. Pollen tetrads had germinated, and the tubes had penetrated the stigma surface and begun growth down the style. Ovules were unpenetrated.

At day 4, the greenhouse material was similar to the 1987 field collections. By day 7, the squashes showed nearly all ovules penetrated by pollen tubes from both self- and outcross pollination. Ovules from the unpollinated stigmas were unpenetrated and had begun to degenerate.

At day 14, ovules developing further had greatly enlarged (Fig. 2), while the nondeveloping ovules showed no size change; but there was an increasing fluorescence from callose accumulation, which is symptomatic of general degeneration (Kho and Baer, 1970; Williams et al., 1984a). The enlarged ovules were balloon-like, and it was difficult to discern the developing embryo. However, a globular embryo was found in several instances above the degenerating synergid at the end of the micropyle 


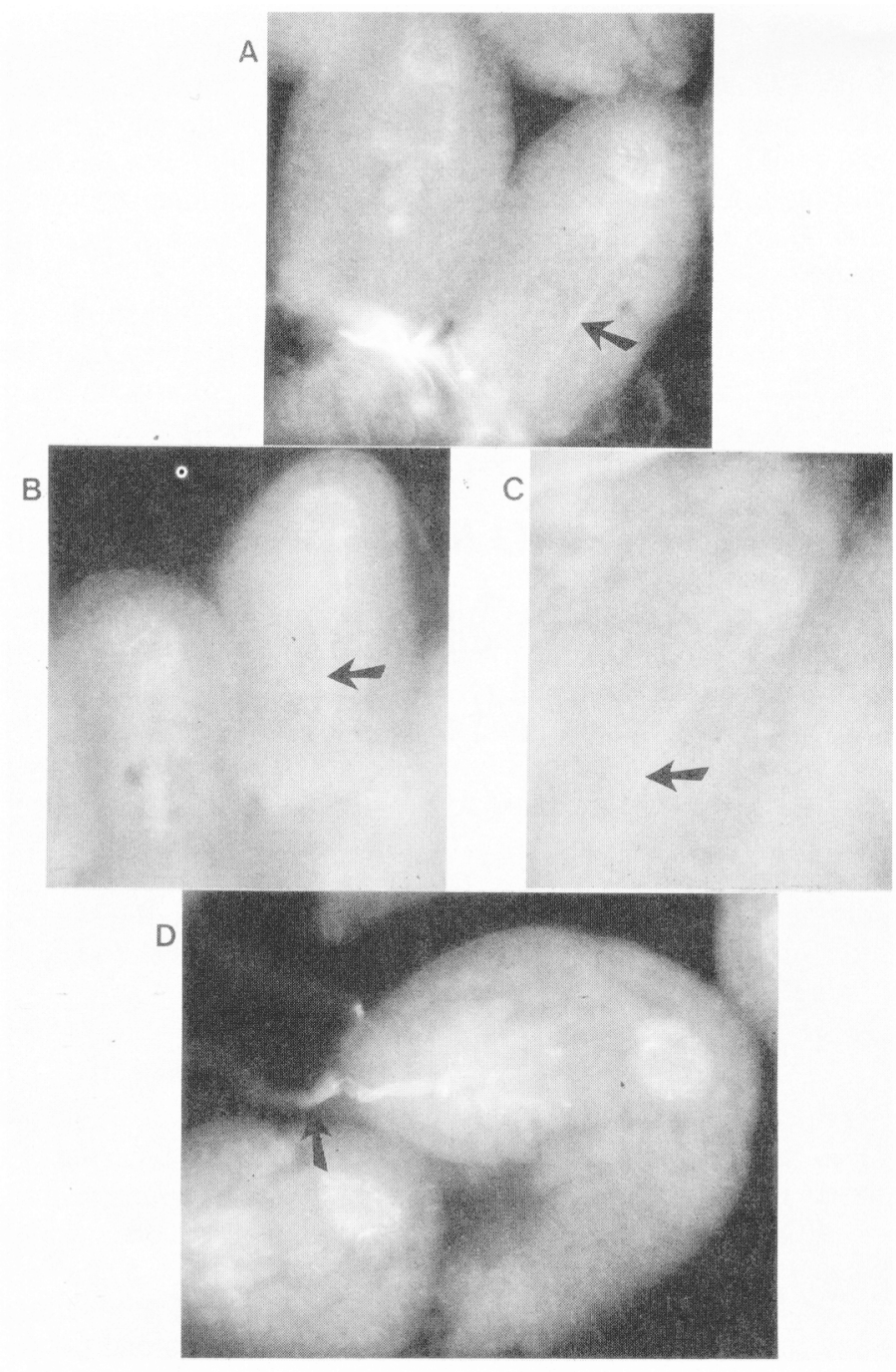

Fig. 1. Comparison of the condition of fixied ovules collected from the field 3 days after pollination in 1987 from $R$. prinophyllum, Minnesota Landscape Arboretum accession no. 790912. (A) Ovules from the cross $8 \times 9$. Note pollen tube extending from the micropyle entrance to the region of the embryo proper in the ovule on the right (arrow). The left ovule appears unpenetrated. Capsule set: 88\%. (B) Ovules of female 8, selfed. Pollen tube is obvious in the right-hand ovule (arrow). Capsule set: $22 \%$. (C) Ovule of female 9, selfed, with entering pollen tube (arrow). Capsule set: 0. (D) Ovule from the cross $9 \times 6$. Pollen tube visible externally (arrow) as it enters the ovule. Capsule set: $79 \%$.

(Fig. 2b). An area of brightly fluorescing callose between the synergid and the embryo fit the description of a callose special wall (Williams et al., 1984a), which is thought to function as a separation of the newly formed sporophyte from maternal tissue. Observations of styles from days 21 and 28. did not add significant information.

Ovule counts. Reproductive success in angiosperms can be expressed by percentages of viable seed produced (Aalders and Hall, 1961; Cope, 1958; Flaschenriem and Ascher, 1979; Lundqvist, 1954; Takahashi, 1973). The reproductive success or failure through seed set in $R$ prinophyllum requires an assessment of initial reproductive potential. Counts of ovules revealed that there were from 275 to 419 per ovary in $R$. prinophyllum. Consequently, the number of potential seeds per female differed significantly $(P<0.01)$. This factor must then
A

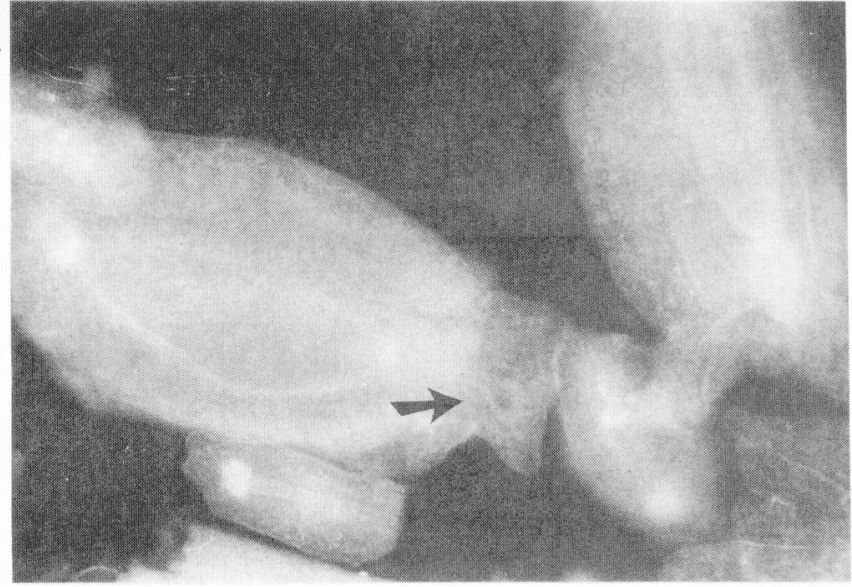

B

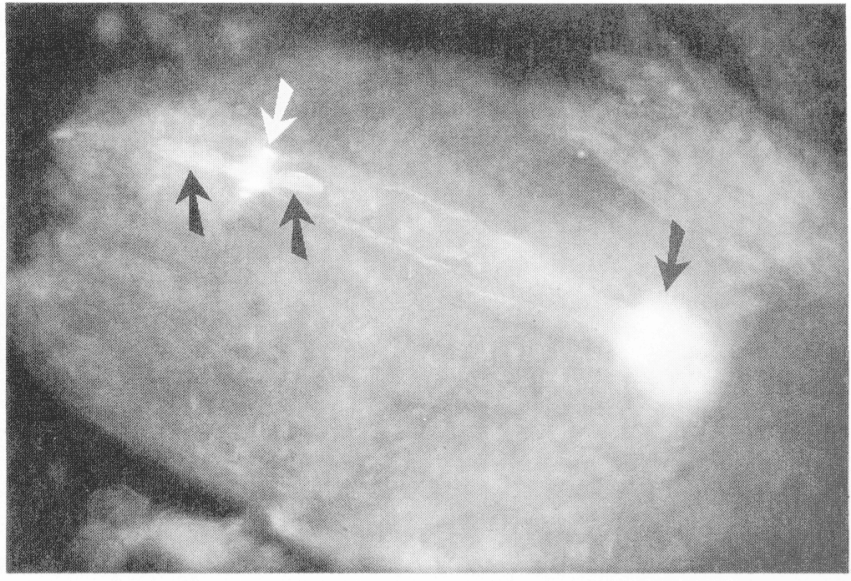

Fig. 2. Ovules of $R$. prinophyllum, Minnesota Landscape Arboretum accession no. 790912, 14 days after pollination. (A) Comparative view of developing vs. degenerating ovules in the cross $\mathrm{C} \times \mathrm{A}$. Note size differences and the increase in generalized fluorescence in the degenerating ovules. Also note development of chalazal ornamentation (arrow) of the integument of enlarged ovules. (B) A developing ovule from the cross $\mathrm{A} \times \mathrm{C}$. The brightly fluorescing circular end is the hypostase (far right arrow). At the opposite end is the degenerating synergid (left arrow), fluorescing callose special wall (white arrow), and globular proembryo (right arrow).

be taken into consideration when evaluating success in seed production.

Capsule set. Self-pollination the first year resulted in a wide range of compatibility, with five clearly self-incompatible individuals (Fig. 3). There were also four plants that were partially self-compatible. This selfing behavior is in contrast to that reported by Whiting (1979) when seven $R$ prinophyllum $(R$. roseum) plants (from a different seed source than used in this research) produced no seed from self-pollination. This variability is not unexpected, however, when viewed in light of past literature regarding self- and interspecific crossings in Rhododendron (Bowers, 1960; Kehr, 1966; Kho and Baer, 1970, 1973; Widrlechner et al., 1982).

Data showing that selfing in five of the nine individuals produced no capsules would suggest that a self-recognition system exists. Lack of capsule set seen in four of the outcross pollinations might also indicate the degree of relatedness among the full-sibling population. Crossing tags were lost on the pollinated flower clusters for three of the crosses, and these appear as $\times$ in Fig. 3 (crosses $5 \times 7,7 \times 5$, and $9 \times 8$ ).

If a SI system were functioning in $R$. prinophyllum, then the 
CAPSULE SET - FEMALE 4

1980

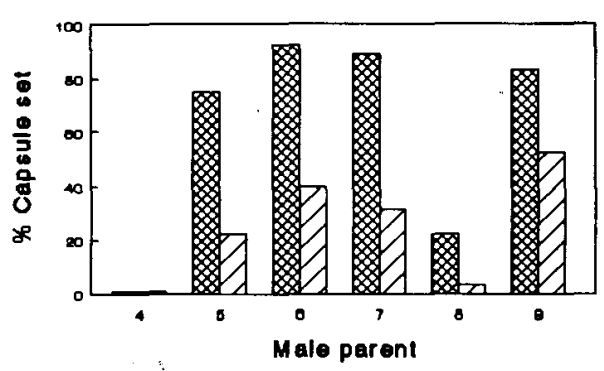

CAPSULE SET - FEMALE 6

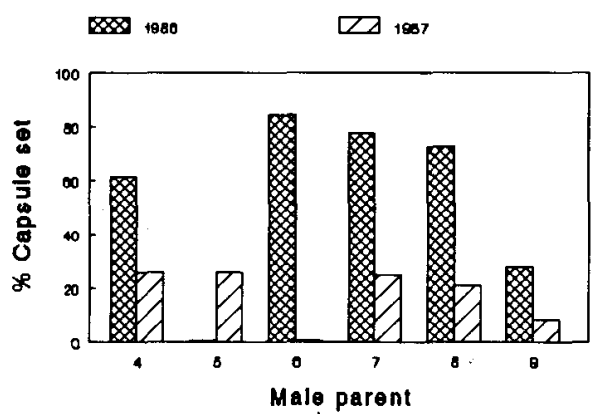

CAPSULE SET - FEMALE 8

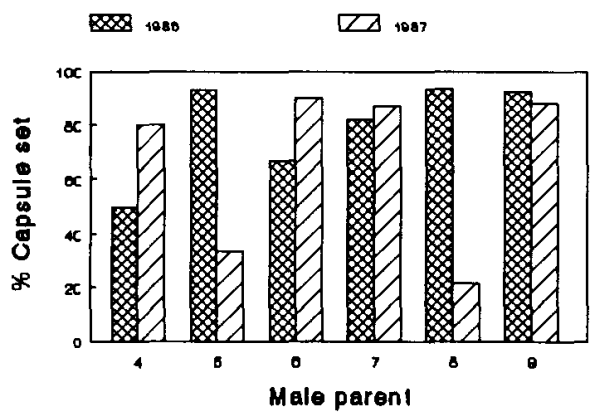

CAPSULE SET - FEMALE 5

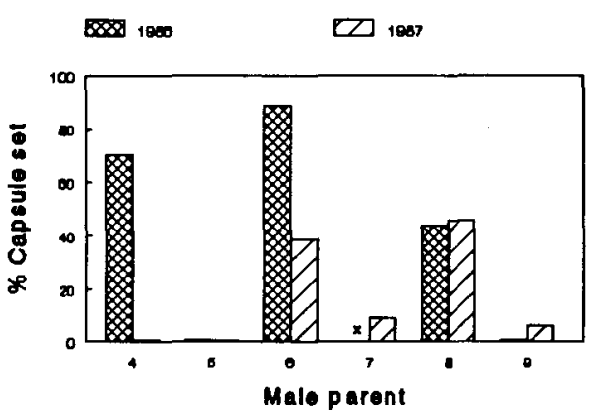

CAPSULE SET - FEMALE 7

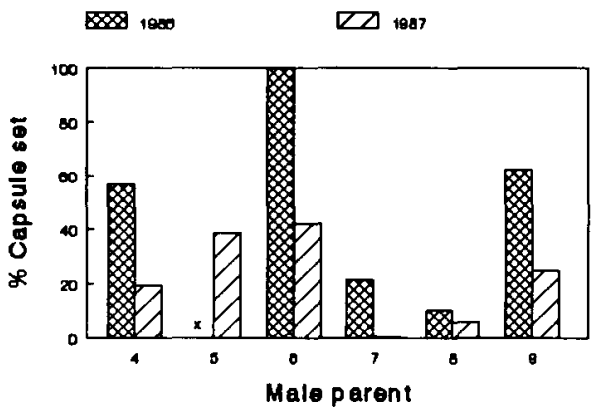

CAPSULE SET - FEMALE 9
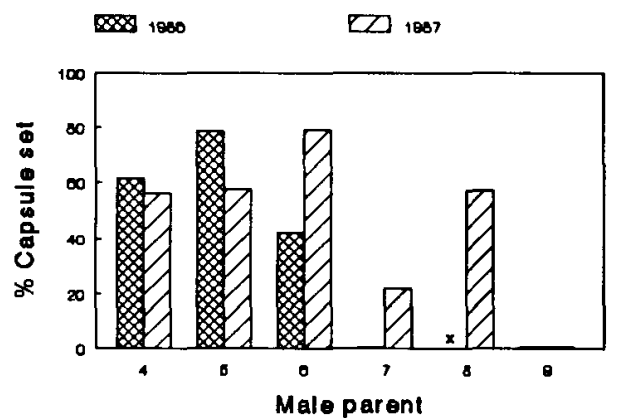

Fig. 3. Comparative capsule set per female for the 1986 and 1987 seasons from $R$. prinophyllum, Minnesota Landscape Arboretum accession no. 790912. Data are missing for three 1986 crosses $(x)$ for which tags were lost. Crosses that resulted in no capsule set are represented by a solid line at the base of the graph.

four plants setting self-capsules could be explained as exhibiting pseudo-self-compatibility, which is the incidence of a range of seed set following self-pollination in plants known to have SI (Darwin, 1876). The 1986 data for capsule set also show large differences in the percentage of capsules set between reciprocal crosses (e.g., crosses $7 \times 8$ and $8 \times 7$ ). Reciprocal differences such as these point to sporophytic as opposed to gametophytic control of self-fertilization.

Despite many pollinations having been made per cross in 1987, the overall number of capsules set was generally less than in 1986 (Fig. 3). Only female no. 8 set any self capsules. Also, the self set for female no. 8 was less than one-fourth $(\approx 22 \%)$ than the capsule set the previous season $(\approx 93 \%)$. However, the percentages of outcross set in 1987 were also much lower.
The overall reduction in capsule set in 1987 was not completely unexpected. Winter 1986-87 had virtually no snow cover, which is unusual for Minnesota. The open winter was preceded by a dry fall and followed by a dry spring and early summer. A hot, dry weather pattern characterized the breeding season. During the 1987 pollination period, temperatures reached 32C.

A second reason for reduced capsule production for the 1987 season is addressed by Wiens (1984) in seed : ovule ratios (S : O). While annual species mature on average $\approx 85 \%$ of their ovules as seed, woody plants are reported as having a $\mathrm{S}: \mathrm{O}$ ratio of only $\approx 33 \%$.

Stephenson (1981) reviews literature pertaining to trends in reproduction of various species on a flower to fruit basis. He concluded that, within a species, the ratio of flowers : fruit can 
vary among populations, among individuals in a population, and from year-to-year in perennial individuals. Seemingly a logical point, this still is important when data on reproductive success are analyzed. Overall fruit : flower ratios for the $R$. prinophyllum population were $51.5 \%$ in 1986 and $31.4 \%$ in 1987 . Considering the harshness of weather conditions and related source/ sink problems, it may well be that $31 \%$ is not really a poor performance.

Seed counts. Seed count data for 1987 were based on 232 capsules (Table 1). Percent seed per capsule is derived as the mean number of developed seeds per capsule divided by the standard number of ovules per capsule from that female. Percent seed per flower pollinated is similarly derived by using the mean number of developed seeds per pollinated flower, rather than per capsule, obtained; this percentage, therefore, more accurately depicts the overall level of reproductive success.

In a compatible cross, if the percentage of flowers that abort or fail to develop represents "normal" abortion of excess flowers, then percent seed per capsule should more accurately reflect the physiological interactions. If woody plants have a fixed $\mathrm{S}$ : O ratio of $\approx 33 \%$ as suggested by Wiens (1984), an interpretation of seed set failure due to any other causes, such as prezygotic SI or postzygotic abortion, should take into account this possible background rate of abortion.

Seed germination. Standard germination of azalea seed at the Univ. of Minnesota Landscape Arboretum involves surfacesowing the cleaned seed on commercially available acid peat and keeping them warm (20C), moist, and in diffuse light until germination occurs. Germination procedures for Rhododendron by other researchers are similar. An acid-based medium of sphagnum peat or oak leaf mold and sharp sand is used (Cox, 1985; Hartmann and Kester, 1975; Kains and McQueston, 1942).

Trials using these methods were all done on seeds from the cross $8 \times 6$, as there was an abundance of seed available. None germinated.

While we found no literature stating that mature dried Rhododendron seed requires a moist-chilling treatment to overcome a secondary dormancy, there had to be some reason seed was not germinating. Arisumi et al. (1988) reported improved germinability in immature $R$. simiarum seed by a cold treatment to either capsules, seed, or synergistically, to both. It seems logical to suspect that some internal dormancy, imposed to prevent matured seed from germinating prematurely in adverse conditions, would be operating in $R$. prinophyllum.

Application of GA is often the next best means of overcoming dormancy (Bewley and Black, 1982; Ellis et al., 1983). Thus, two more 50 -seed samples were taken from cross $8 \times 6$. One was treated with $500 \mathrm{ppm} \mathrm{GA}$ and the other with $1000 \mathrm{ppm}$, since we found no suitable rates in the literature. Germination occurred in both dishes $\approx 10$ days after sowing, and a final count made 3 days later yielded an average of $17 \%$ for the two germination treatments. Compared to previous results, this one seemed to support the use of the growth regulator; an average of the two treatments compensates for the inability to replicate the trials for seed from each cross at several GA levels.

Difficulty in assessing quality of azalea seed is increased because of the inclusion of seed with low vigor in the seed lots. Seeds of poor quality will be represented when randomly sampling lots for germination trials. The averaged results of the two germination treatments are listed as percent germination in Ta-

Table 1. Summary of female reproductive success in 1987 by percent capsule set, percent seed set per capsule, percent seed set per flower pollinated, and percent germination in Rhododendron prinophyllum, Minnesota Landscape Arboretum accession no. 790912.

\begin{tabular}{|c|c|c|c|c|c|c|c|c|c|}
\hline$\cdot$ & $\begin{array}{c}\text { Capsule } \\
\text { set } \\
(\%) \\
\end{array}$ & $\begin{array}{c}\text { Seed/ } \\
\text { capsule } \\
(\%)\end{array}$ & $\begin{array}{c}\text { Seed/ } \\
\text { flower } \\
\text { pollinated } \\
(\%)\end{array}$ & $\begin{array}{c}\text { Germi- } \\
\text { nation } \\
(\%)\end{array}$ & & $\begin{array}{c}\text { Capsule } \\
\text { set } \\
(\%) \\
\end{array}$ & $\begin{array}{c}\text { Seed/ } \\
\text { capsule } \\
(\%)\end{array}$ & $\begin{array}{c}\text { Seed/ } \\
\text { flower } \\
\text { pollinated } \\
(\%)\end{array}$ & $\begin{array}{c}\text { Germi- } \\
\text { nation } \\
(\%)\end{array}$ \\
\hline \multicolumn{5}{|c|}{ Female 4} & \multicolumn{5}{|c|}{ Female 7} \\
\hline $\begin{array}{r}x 4 \\
\times 5 \\
\times 6 \\
\times 7 \\
x 8 \\
\times 9 \\
\text { Avg }\end{array}$ & \begin{tabular}{r}
\multicolumn{1}{c}{0} \\
22.2 \\
40.0 \\
31.6 \\
3.0 \\
52.4 \\
24.9
\end{tabular} & $\begin{array}{c}0 \\
15.22 \\
46.98 \\
18.03 \\
19.37 \\
16.35 \\
19.04\end{array}$ & $\begin{array}{r}0 \\
3.38 \\
18.80 \\
5.69 \\
5.88 \\
8.57 \\
6.08\end{array}$ & $\begin{array}{r}0 \\
4.0 \\
5.0 \\
12.0 \\
4.0 \\
9.0 \\
6.0\end{array}$ & $\begin{array}{r}\times 4 \\
\times 5 \\
\times 6 \\
\times 7 \\
\times 8 \\
\times 9 \\
\text { Avg }\end{array}$ & $\begin{array}{c}19.4 \\
38.9 \\
42.1 \\
0 \\
5.9 \\
25.0 \\
21.9\end{array}$ & $\begin{array}{c}24.29 \\
23.26 \\
26.53 \\
0 \\
8.66 \\
17.44 \\
17.11\end{array}$ & $\begin{array}{c}4.70 \\
7.94 \\
11.17 \\
0 \\
5.10 \\
4.36 \\
4.97\end{array}$ & $\begin{array}{c}12.0 \\
12.0 \\
16.0 \\
0 \\
0 \\
6.0 \\
11.0\end{array}$ \\
\hline \multicolumn{5}{|c|}{ Female 5} & \multicolumn{5}{|c|}{ Female 8} \\
\hline $\begin{array}{r}x 4 \\
\times 5 \\
\times 6 \\
\times 7 \\
x 8 \\
\times 9 \\
\text { Avg }\end{array}$ & \begin{tabular}{r}
\multicolumn{1}{c}{0} \\
0 \\
38.5 \\
9.1 \\
45.5 \\
5.9 \\
16.5
\end{tabular} & $\begin{array}{r}0 \\
0 \\
32.50 \\
7.66 \\
21.35 \\
6.92 \\
11.07\end{array}$ & $\begin{array}{c}0 \\
0 \\
11.54 \\
6.96 \\
9.71 \\
4.08 \\
3.57\end{array}$ & $\begin{array}{l}0 \\
0 \\
8.0 \\
9.0 \\
3.0 \\
0 \\
3.0\end{array}$ & $\begin{array}{r}x 4 \\
\times 5 \\
\times 6 \\
\times 7 \\
\times 8 \\
\times 9 \\
\text { Avg }\end{array}$ & $\begin{array}{l}80.0 \\
33.3 \\
90.0 \\
86.7 \\
21.7 \\
88.0 \\
66.6\end{array}$ & $\begin{array}{l}22.67 \\
13.92 \\
73.13 \\
36.09 \\
96.84 \\
38.75 \\
31.88\end{array}$ & $\begin{array}{r}16.88 \\
4.16 \\
6.58 \\
29.14 \\
2.11 \\
3.41 \\
24.92\end{array}$ & $\begin{array}{l}1.0 \\
0 \\
1.0 \\
0 \\
6.0 \\
1.0 \\
2.0\end{array}$ \\
\hline \multicolumn{5}{|c|}{ Female 6} & \multicolumn{5}{|c|}{ Female 9} \\
\hline $\begin{array}{r}x 4 \\
\times 5 \\
\times 6 \\
\times 7 \\
\times 8 \\
\times 9 \\
\text { Avg } \\
\end{array}$ & $\begin{array}{c}25.8 \\
25.8 \\
0 \\
25.0 \\
21.1 \\
8.6 \\
17.7 \\
\end{array}$ & $\begin{array}{c}26.20 \\
39.41 \\
0 \\
38.31 \\
67.32 \\
58.97 \\
38.87 \\
\end{array}$ & $\begin{array}{c}6.76 \\
10.17 \\
0 \\
9.57 \\
14.18 \\
5.05 \\
7.70 \\
\end{array}$ & $\begin{array}{c}38.0 \\
14.0 \\
0 \\
23.0 \\
11.0 \\
29.0 \\
19.0 \\
\end{array}$ & $\begin{array}{r}\times 4 \\
\times 5 \\
\times 6 \\
\times 7 \\
\times 8 \\
\times 9 \\
\text { Avg } \\
\end{array}$ & $\begin{array}{c}56.5 \\
57.9 \\
78.9 \\
21.7 \\
57.1 \\
0 \\
45.4 \\
\end{array}$ & $\begin{array}{c}14.39 \\
14.51 \\
25.18 \\
78.14 \\
17.88 \\
0 \\
13.31 \\
\end{array}$ & $\begin{array}{r}8.13 \\
8.41 \\
18.56 \\
16.98 \\
8.94 \\
0 \\
7.51 \\
\end{array}$ & $\begin{array}{c}21.0 \\
11.0 \\
14.0 \\
9.0 \\
1.0 \\
0 \\
11.0 \\
\end{array}$ \\
\hline
\end{tabular}


ble 1 . Germination in general was poor. Seed from cross $8 \times 6$ had $1 \%$ germination in the full experiment compared with $17 \%$ in the development of the technique. So, when looking at the final germination results, one might question whether the GA treatments were beneficial. Poor germination may reflect the inherent problems associated with the relatedness of a full-sibling population.

Levels of reproductive success. Reproductive success was greatly reduced at each successive criterion measured (Table 1). The best germination from the cross $6 \times 4$ resulted in only $38 \%$ germination and this is, of course, no indication of the ultimate survival of those seedlings to reproductive maturity. With a mean of 374 ovules per capsule in female 6 , this suggests that just $2.6 \%$ of initial ovules produced will reach the seedling stage. Although factors of cultural conditions for these plants certainly play a role in their ability to produce seed, this is still a very poor reproductive output if viewed by traditional measures.

Theoretical considerations. SI has been assumed to be the cause of reproductive failure in other attempts at selfing in various Rhododendron spp. (Cox, 1985; Yamaguchi, 1980). However, evidence from microscopic examination of pollen-pistil interaction in the present research does not support the operation of a genetic prefertilization barrier to selfing. Therefore, by definition, genetic SI cannot be operating in $R$. prinophyllum. However, this does not suggest that there is no self-recognition event. A discrimination between self-matings and sib matings exists that preferentially allows a degree of sibbing over levels of selfing. It is also apparent that the level of reproduction attained for a given self or cross for each female (or male) and for the population as a whole is greatly influenced by the environment and resources available in a particular season. The combination of these factors, along with evidence from ovule development following self- and cross-pollinations, points rather conclusively to what in the literature has been termed late-acting SI or postzygotic abortion; both of which are thought to be polygenic in nature (Cope, 1962 Crowe, 1971; Seavey and Bawa, 1986; Williams et al., 1984a, 1984b).

The nature of this late-acting system in $R$. prinophyllum is difficult to define because the system operates beyond formation of a zygote. It is difficult to pinpoint the precise moment, either microscopically or macroscopically, of any active controlled breakdown or to distinguish it from inbreeding depression caused by the passive buildup of recessive deleterious or lethal genes. Seavy and Bawa (1986) suggested the late-acting system to occur under temporal failure from selfing, genetic segregation expressed before germination, and success of embryo rescue. Failure of postzygotic development at a range of stages and failure of embryo rescue suggest inherent genetic failure. Data from capsule set might be interpreted to indicate that there is a reproductive barrier to selfing in $R$. prinophyllum. The fact that a continuum of failure exists in the crosses and selfs suggests that inbreeding also exerts an influence.

Any genetic system, pre- or postzygotic, that results in a certain level of heterozygosity, will function to preserve genetic diversity and to ensure ultimate survival of a population. Survival during periods of isolation requires some level of tolerance to inbreeding. With Rhododendron, the large number of potential seeds, preferentially combined with postzygotic abortion, might function this way.

Classic SI is based on recognition. The ultimate gene products that can inhibit incompatible pollen tubes or, perhaps less likely, promote compatible pollen tubes function to select paternal genotypes. Sexual selection, where competition and genetic differences result in different levels of reproductive success among viable individuals of the same sex (Darwin, 1876; Marshall and Ellstrand, 1986; Willson, 1979), is considered a primary evolutionary force. It is invoked when differentiating between success rates of various male parents in mixed pollinations (Hill and Lord, 1986). In a late-acting system, where incoming pollen tubes are not discriminated against, mate selection must occur at the level of the zygote or embryo via selective abortion. This pattern has invariably been viewed as wasteful due to sterilization of ovules in which there has already been a considerable maternal investment (Lewis, 1979) and has thus been considered anomalous or maladaptive. However, the number of species in which late-acting systems have been described is increasing despite the difficulties in proving their operation experimentally (Bookman, 1984; Brandham and Owens, 1978; Cope, 1958, 1962; Crowe, 1971; Miri and Bubar, 1965; Spiss and Paolillo, 1969).

If late-acting phenomena are considered maladaptive, then what are the implications for evolutionary survival of Rhododendron? First, this method of sexual selection may not be as inefficient as originally thought (Seavey and Bawa, 1986; Stephenson, 1981). The production of excess flowers to attract pollinators, increase male function, and optimize mate selection would be immediately wasteful if the amount of maternal investment were excessive. Instead, a selective investment might function to reduce the commitment of resources to offspring that are less likely to succeed (Westoby and Rice, 1982).

The Ericaceae is very diverse, and plants in this family tend to occupy nutrient-poor acidic environments. Resource availability affecting selection could result in cyclical seasons of "boom" and "bust" reproduction and might indeed argue for a selective advantage in retention of zygotes until a balance in investment and resources could be achieved. Evolution to adapt to periodic extremes of available resources might well result in a deferment of mate selection through polygenic late-acting systems.

Another way of looking at late-acting systems, evolutionarily, is as a stepping stone from inbreeding depression, which is completely wasteful in that it produces progeny destined to fail, to the more advanced SI systems. As such, Rhododendron, and perhaps the Erica family, might be viewed as representing an increment in the evolutionary ladder of reproductive mode. So, while somewhat wasteful, the late-acting systems still succeed on a certain level. Or, it might be that these plants are relics that, while maladaptive, still survive well enough within their own environment. In this event, it may be that any selective advantage would then depend heavily on the high reproductive potential of Rhododendron spp. that flower profusely for many years and produce hundreds of seeds per capsule (Williams et al., 1984b).

\section{Literature Cited}

Aalders, L.E. and LV. Hall. 1961. Pollen incompatibility and fruit set in lowbush blueberries. Can. J. Genet. Cytol. 3:300-307.

Arisumi, K., E. Matsuo, Y. Sakata, and K. Tsukiashi. 1988. The improvement of terminability of the immature Rhododendron seeds by cold treatment. Mem. Faculty Agr. Kagoshima Univ. 24:123128.

Ascher, P.D. 1976. Self-incompatibility systems in floriculture crops. Acta Hort. 63:205-215.

Bewley, J.D. and M. Black. 1982. Physiology and biochemistry of seeds in relation to germination, vol. 2. Springer-Verlag, Berlin. 
Bookman, S.S. 1984. Evidence for selective fruit production in Asclepias. Evolution 38:72-86.

Bowers, C.G. 1960. Rhododendrons and azaleas. Macmillan, New York. p. 184-186.

Brandham, P.E. and S.J. Owens. 1978. The genetic control of selfincompatibility in Gasteria (Liliaceae). Heredity 40:165-169.

Cope, F.W. 1958. Incompatibility in Theobroma cacao. Nature (London) 181:279.

Cope, F.W. 1962. The mechanism of pollen incompatibility in Theobroma cacao L. Heredity 17:157-182.

Cox, P.A. 1985. The smaller Rhododendrons. Timber Press, Portland, Or e.

Creech, John L. 1955. An embryological study in the Rhododendron subgenus Anthodendron Endl. Bot. Gaz. 116:234-243.

Crowe, L.K. 1971. The polygenic control of outbreeding in Borago officianalis. Heredity 27:111-118.

Darwin, C. 1876. The effects of cross and self-fertilization in the vegetable kingdom; Murray, London.

Ellis, R.H., T.D. Hong, and E.H. Roberts. 1983. Long-term seed storage of major temperate fruits. (From: Intl. Board Plant Genet. 1985.) Vitis 22:211-219.

Flaschenriem, D.R. and P.D. Ascher. 1979. Pollen tube expression of pseudo-self-compatibility in Petunia hybrida. Theoretical Applied Genet. 54:97-101.

Hartmann, H.T. and D.E. Kester. 1975. Plant propagation, principles and practices. Prentice Hall, Englewood Cliffs, N.J. p. 153-154.

Hill, J.P. and E.M. Lord. 1986. Dynamics of pollen tube growth in the wild radish, Raphanus raphanistrum (Brassicaceae). I. Order of fertilization. Evolution 40:1328-1333.

Kains, M.G. and L.M. McQueston. 1942. Propagation of plants. Orange Judd Publishing, New York.

Kehr, A.E. 1966. Breeding for a purpose. Quart. Bul. Amer. Rhododendron Soc. 20:130-141.

Kho, Y.O. and J. Baer. 1968. Observing pollen tubes by means of fluorescence. Euphytica 17:298-302.

Kho, Y.O. and J. Baer. 1970. A microscopical research on the incompatibility in the cross Rhododendron impeditum $\times R$. williamsianum. Euphytica 19:303-309.

Kho, Y.O. and J. Baer. 1973. Improving the cross Rhododendron Impeditum $\times R$. 'Elizabeth' by temperature treatment. Euphytica 22:234-238.

Lewis, D. 1979. Sexual incompatibility in plants. University Park Press, Baltimore.

Liedl, B.E. and N.O. Anderson. 1987. SIGMAS Version 2.0 A software program for self incompatibility genetic modeling. Pl. Cell Incomp. Nwsl. 19:1-2.
Lundqvist, A. 1954. Studies on self-sterility in Rye, Secale cereale L. Hereditas 40:278-294.

Marshall, D.L. and N.C. Ellstrand. 1986. Sexual selection in Raphanus sativus: Experimental data on non-random fertilization, maternal choice, and consequences of multiple paternity. Amer. Naturalist 127:446-461.

Miri, R.K. and J.S. Bubar. 1965. Self-incompatibility as an outcrossing mechanism in Birdsfoot Trefoil (Lotus corniculatus). Can. J. Plant Sci. 45:411-418.

Seavey, S.R. and K.S. Bawa. 1986. Late-acting self-incompatibility in angiosperms. Bot Rev. 52:195-219.

Spiss, L. and D.J. Paolillo, Jr. 1969. Semi-vitro methods in the study of compatibility in Birdsfoot Trefoil (Lotus comiculatus L.). Crop Sci. 9:173-176

Stephenson, A.G. 1981. Flower and fruit abortion: Proximate causes and ultimate functions. Ann. Rev. Ecol. Syst. 12:253-279.

Takahashi, H. 1973. Genetical and physiological analysis of pseudoself compatibility in Petunia hybrids. Jpn. J. Genet. 48:27-33.

Westoby, M. and B. Rice. 1982. Evolution of the seed plants and inclusive fitness of plant tissues. Evolution 36:713-724.

Whiting, G.C. 1979. Self-incompatibility in five Rhododendron species and one hybrid. Interspecific compatibility relationships in six Rhododendron species and one hybrid. PhD Diss., Univ. of Minnesota, St. Paul. p. 65-84.

Widrlechner, M., H. Pellett, and P. Ascher. 1982. Unreduced gametes in azalea hybrids: a possible breeding method for using promising azaleas of low fertility. J. Amer. Rhododendron Soc. 36:98-101.

Wiens, D. 1984. Ovule survivorship, brood size, life history, breeding systems, and reproductive success in plants. Oecologia 64:47-53.

Williams, E.G., R.B. Knox, and J.L. Rouse. 1982. Pollination subsystems distinguished by pollen tube arrest after incompatible interspecific crosses in Rhododendron (Ericaceae). J. Cell Sci. 53:255277 .

Williams, E.G., R.B. Knox, and V. Kaul. 1984a. Post-pollination callose development in ovules of Rhododendron and Ledum (Ericaceae): Zygote special wall. J. Cell Sci. 69:127-135.

Williams, E.G., V. Kaul, J.L. Rouse, and R.B. Knox. 1984b. Apparent self-incompatibility in Rhododendron ellipticum, $R$. championae and $R$ amamiense: A post-zygotic mechanism. Plant Cell Incompatibility Nwsl. 16:10-11.

Williams, E.G., J.L. Rouse, and V. Kaul. 1985. Early events in the embryo sac after intra and interspecific pollinations in Rhododendron kawakamii and Rhododendron retusum. Can. J. Bot 64:282-291.

Wilson, M.F. 1979. Sexual selection in plants. Amer. Naturalist 113:777790.

Yamaguchi, S. 1980. Field tests of self-incompatibility in Rhododendron kiusianum. Plant Incompatibility Nwsl. 12:16-23. 